\title{
Serum Zinc Status in Post Menopausal Women Attending in a Tertiary Care Hospital of Bangladesh
}

\author{
Ferdous N ${ }^{\mathrm{a}}$, Mishu FA ${ }^{\mathrm{b}}$, Shamsunnahar ${ }^{\mathrm{c}}$, Islam F${ }^{\mathrm{d}}$, Sejooti SS
}

\begin{abstract}
Background: Nutritional needs change throughout the various stages of life. While overall caloric needs tend to decrease with age, the requirements for individual micronutrients do not decrease. In fact, the needs for some micronutrients actually increase with age. The risk of nutritional disturbances mainly trace elements deficiencies is high during postmenopause causing or intensifying serious clinical symptoms.

Methods: This cross-sectional study was carried out in the Department of Biochemistry, Mymensingh Medical College in collaboration with the Department of Obstetrics and Gynecology, Mymensingh Medical College Hospital during the period from July 2013 to June 2014. A total of 100 subjects were included in this study. Among them 50 apperantly healthy postmenopausal womenaged between 45-70 years were considered as case and another 50 regular menstruating premenopausal women aged between 30-40 years were selected as control.
\end{abstract}

Results: The mean age of case and control groups was $50.5 \pm 2.3$ years and $36.5 \pm 4.4$ years respectively. In this study serum zinc levels in cases and controls were $71.54 \pm 5.69 \mathrm{ig} / \mathrm{dl}$ and $74.68 \pm 5.453 \mathrm{ig} / \mathrm{dl}$ respectively, and there was significant difference $(p<0.01)$.

Conclusion: Serum zinc level was significantly decreased in postmenopausal group in comparison to premenopausal women $(p<0.01)$. Estimation of serum zinc levels might be incorporated in every postmenopausal for possible prevention of complications.

Key Words: Micronutrients, post menopausal women, serum zinc level.

(BIRDEM Med J 2019; 9(2): 147-150)

\section{Introduction}

Menopause is defined as the permanent cessation of menstruation for a period of longer than one year. Natural menopause is a gradual process. Unless brought about by surgery, chemotherapy or other factors, natural

\section{Author Information}

a. Dr. Nadia Ferdous, Assistant Professor of Biochemistry, Tairunnesa Memorial Medical College, Dhaka

b. Dr. Farzana Akonjee Mishu, Assistant Professor of Biochemistry, Bangladesh Institute of Research \& Rehabilitation In Diabetes, Endocrine \& Metabolic Disorders (BIRDEM), Dhaka, Bangladesh.

c. Dr. Shamsunnahar, Assistant Professor of Biochemistry, President Abdul Hamid Medical College, Kishorgonj

d. Dr. Fahmida Islam, Lecturer of Biochemistry, Ibrahim Medical College, Dhaka.

e. Dr.Shabnam Sarwar Sejooti, Assistant Professor of Biochemistry. Tairunnesa Memorial Medical College, Dhaka.

Address of Correspondence: Dr. Nadia Ferdous, Assistant Professor of Biochemistry, Tairunnesa Memorial Medical College, Dhaka. Email: suchinf@gmail.com

Received: October 31, 2018

Accepted: February 28, 2019 or physiologic menopause occurs in most women between the ages of 47-55 years and the average age of natural menopause is 51 years. ${ }^{1}$ Although menopause is a natural biologic process occurring in the body due to changing hormone levels across the life span of a woman, it probably has the greatest impact on health. ${ }^{2}$ Women face various physiological, psychological and biochemical changes during this period. The most common symptom reported by postmenopausal women is hot flush or night sweats ( $80 \%)$. The other symptoms may include tiredness, mood swings, insomnia, mental exhaustion, joint and muscular discomfort, irritability, headache, dryness of vagina, loss of libido, urinary incontinence etc. ${ }^{3}$ In this period of life the risk of osteoporosis, cardiovascular diseases, arterial hypertension, impairment of glucose metabolism, breast cancer and degenerative cognition diseases rises. The risk of nutritional disturbances, particularly trace elements and vitamin deficiencies is also high during 
this period. ${ }^{4,5}$ It is the time when steroid hormone deficiency is often accompanied by essential mineral deficiencies causing or intensifying the clinical symptoms ${ }^{6}$

Trace elements are essential co- factors for enzymes, involved in the synthesis of various bone matrix constituents. They are also involved in the interaction of many enzyme reactions necessary for the transmission of nerve impulses, temperature regulation, detoxification, energy production etc. ${ }^{7}$ Nutritional needs change throughout the various stages of life. While overall caloric needs tend to decrease with age, the requirements for individual micronutrients (vitamins and nutritionally-essential minerals) do not decrease. In fact, the needs for some micronutrients, actually increase with age. Adults older than 50 years, require higher intakes of these micronutrients. Alteration of the levels of trace elements results in, altered immune functions, increased oxidative stress, impaired cognitive functions, glucose intolerance, osteoporosis etc in postmenopausal age group . 7

Zinc ( $\mathrm{Zn})$ is an important essential trace element present in all body tissues and fluids needed for catalytic, structural and regulatory functions in the body. ${ }^{8,9}$ It is intimately involved in the maintenance of the immune function. Zn deficiency is a serious problem in developing countries. Many studies have shown the adverse effects on growth and morbidity as well as the prevention of infection by $\mathrm{Zn}$ supplementation. ${ }^{10}$ Some researchers encounter elderly patients complaining of taste impairment, stomatitis , nausea, anorexia, delayed healing of decubitus ulcer, behavior abnormalities in the daily medical practice. These symptoms can be improved by the supplementation of $\mathrm{Zn} .{ }^{11}$ As a woman ages, her $\mathrm{Zn}$ status may alter for several reasons. Although Zn deficiency appears to be common in older women as a result of low dietary intake or reduced dietary absorption, increased serum zinc levels may observe in postmenopausal women which may be the affect of increased bone resorption because of estrogen deficiency. $\mathrm{Zn}$ excess may result in anaemia, electrolyte imbalance, lethargy and symptoms of copper and iron deficiency, weak immune system, nausea, vomiting, gastrointestinal irritation, hypocupremia, red blood cell microcytosis and nutropenia. ${ }^{12,13}$ The significance of zinc in menopausal nutrition and public health was recognized relatively recently. Since then, zinc insufficiency has been recognized by a number of experts as an important public health issue, especially in developing countries. ${ }^{14}$

\section{Methods}

The cross-sectional study was corried out at Mymensingh Medical College Hospital from July 2013 to June 2014 to evaluate the serum level of $\mathrm{Zn}$ in 50 apparently healthy postmenopausal ( 45-60 years) women and compared with 50 healthy premenopausal (30-40 years ) women. Pre menopausal women were treated as control group. Post-menopausal women had at least one year of amenorrhea. None had received estrogen therapy or any supportive treatment for menopausal symptoms for at least 6months prior to study. The study protocol was approved by the institutional review committee and written informed consent was obtained from all the participants prior to their enrolment into this study.

Study population and collection of samples: Postmenopausal women, who were attending the outpatient department of Obstetrics and Gynecology of Mymensingh Medical College Hospital were enrolled by purposive sampling technique. Post-menopausal women with the previous history of diabetes, hypertension and other endocrine disorders, hormonal replacement therapy, surgical menopause women were excluded from the study. Data were collected in a predesigned data collection sheet. The variables included were - age, height, weight, family history. About $3 \mathrm{ml}$ of blood was collected aseptically with venipuncture from all participants for estimation of serum $\mathrm{Zn}$ levels.

\section{Estimation serum Zn}

Zn was determined by colorimetric method with 2-(5Brom-2-pyridylazo)-5-[-N-propyl-N-(3sulfopropyl)amino]-phenol. The results were analyzed and values were expressed as mean $\pm \mathrm{SD}$. The level of significance was determined by employing Student's unpaired $t$ test. Only when the $\mathrm{p}$ value was less than 0.05 , the difference between two groups were considered as statistically significant.

\section{Results}

In the present study, out of 100 subjects 50 apparently healthy postmenopausal women were selected as case and 50 premenopausal women as control. Different variables of the subjects were being analyzed and compared between case and control. It was observed that mean $\mathrm{Zn}$ was $74.68 \pm 5.453(\mathrm{ig} / \mathrm{dl})$ for cases and $71.54 \pm 5.694(\mathrm{ig} / \mathrm{dl})$ for controls. The difference in mean serum $\mathrm{Zn}$ levels were very significant $(\mathrm{p}<0.01)$ (Table I) 
Table I Clinical and Biochemical Characteristics of the study subjects $(\mathrm{N}=100)$

\begin{tabular}{lccc} 
Variables & Mean $\pm \mathrm{SD}$ (cases) & Mean $\pm \mathrm{SD}$ (controls) & P value \\
\hline Age & $56.5 \pm 2.3$ & $36.5 \pm 4.4$ & $<0.001$ \\
Height $(\mathrm{cm})$ & $149.21 \pm 10.12$ & $150.31 \pm 11.42$ & $>0.05$ \\
Weight $(\mathrm{kg})$ & $57.43 \pm 8.41$ & $58.46 \pm 7.39$ & $>0.05$ \\
Systolic BP (mm Hg) & $140 \pm 6.15$ & $130 \pm 5.38$ & $<0.001$ \\
Diastolic BP (mmHg) & $85 \pm 2.44$ & $80 \pm 4.21$ & $<0.01$ \\
Zn (ig/dl) & $74.68 \pm 5.453$ & $71.54 \pm 5.694$ & $<0.01$ \\
\hline
\end{tabular}

(Student's t test was used to analyse the data between groups)

\section{Discussion}

As a woman ages, her Znstatus may alter for several reasons. Although zinc deficiency appears to be common in older women as a result of low dietary intake or reduced dietary absorption, increased serum Znlevels may observe in post-menopausal women which may be the affect of increased bone resorption because of estrogen deficiency. Zn excess may result in anaemia, electrolyte imbalance, lethargy and symptoms of copper and iron deficiency, weak immune system, nausea, vomiting, gastrointestinal irritation, hypocupremia, red blood cell microcytosis and nutropenia.$^{15}$

In this study, we observed significant decreased in serum $\mathrm{Zn}$ level in post-menopausal women compared to that of control. This result is consistent with the study of Grochans, et al., Bureau et al. ${ }^{6,16}$ The possible cause may be the lowering of serum albumin in postmenopausal women, as albumin is known to be a major carrier for zinc. But the result of our study is differing from the result of Bednarek-Tupikowska. ${ }^{4}$ Increased serum $\mathrm{Zn}$ in post-menopausal women may be the effect of increased bone resorption because of estrogen deficiency in post-menopausal period. While some other researches Naveenta and Khushdeep, Ansar et al. did not find any significant difference in the serum $\mathrm{Zn}$ level between pre and postmenopausal women . ${ }^{17,18}$

$\mathrm{Zn}$ is nutritionally essential element needed for catalytic, structural and regulatory functions for all forms of life. The significance of $\mathrm{Zn}$ in menopausal nutrition and public health was recognized relatively recently. Since then, $\mathrm{Zn}$ insufficiency has been recognized by a number of experts as an important public health issue, especially in developing countries . ${ }^{10}$

\section{Conclusion}

As post-menopausal women are exposed to greater risk of serum biochemical changes and possibility of nutritional disturbances particularly trace elements and vitamin deficiencies and risk of age related diseases is very high during this period, these adverse changes in serum should be taken into consideration for early diagnosis and prevention of menopause related diseases. Dietary supplementation may be necessary especially where levels are significantly reduced. Therefore, further study should be done to find out the underlying mechanism of alteration of serum zinc in post menopausal women.

Conflict of interest: Nothing to declare.

\section{References}

1. Padubidri VG, Daftari SN. Change in Bourne Shaw's Text Book of Gynaecology. editors. 13th ed.Elsevier, New Delhi2004. pp . $56-58$

2. Baber R . Phytoestrogens and post reproductive health . Maturitas, 2010.66 : 344-49

3. Rahman.Menopausal symptoms assessment among middle age women in Kushtia, Bangladesh.Bmc Research Notes ,2011;4:188.

4. Bednarek - Tupikowska G, Jodkowska A, Antonowicz Juchiniewicz J . Zinc, Copper, Manganese and selenium status in pre and post menopausal women during sex hormone therapy . Adv Clin Exp Med, 2010; 19(3) : 337-345 .

5. Davis SR. Menopause : New therapies . MJA , . 2003; 178 : 634-7.

6. Bureau B, Anderson RA, Arnaud J, Raysiguier Y. Trace mineral status in post menopausal women: impact of hormonal replacement therapy. J Trace Elem Med Biol.2002; 16(1): 9-13.

7. Kirk D, Fish S.A. Medical management of osteoporosis . Am J Mang Care , 2004;10 : 39-43 
8. Hambidge M. Human zinc deficiency. J Nutr, 2000; 130(5S Suppl):1344S-1349S.

9. Hambidge KM. Zinc. In: Trace elements in human and animal nutrition. Mertz, W., ed. 5th, 1987;Vol. 1., p.1-137.

10. Kogirima M, Kurasawa R, Kubori S, Sarukura N, Nakamori M ,Okada S, kamioka H, Yamamoto. Ratio of low serum zinc levels in elderly Japanese people living in the central part of Japane. J Clin Nut.2007; 61:375-381.

11. Kurasawa R, Kubori S, Kamioka H, Okada S, Matsumura ,OZinc deficiency in aged residents and lowered serumzincconcentration as population level in the same rural region. Biomed Res Trace Elements . 2005; 16:60-64 .

12. Mutlu M, Argun M, Saraymen R, Yazar S . Mgnesium, zinc and copper status in osteoporotic, osteopenic and normal postmenopausal women. The Journal of International Medical Research 2007; $35: 692-695$.
13. Martin-Lagos F, Navarro-Alarcon M, Terres- Martos C, LopezGarcia de la Serran H., Perez-Valero V, Lopez- Martinez MC.. Zinc and Copper concentrations in serum from Spanish women during pregnancy. Biol Trace Elem Res. 1998;61(1): 61-70.

14. Prasad AS.Discovery of human zinc deficiency: 50 years later. J Trace Elem Med Biol. 2012; 26(2-3):66-69.

15. Nedrow A, Miller J, Walker M, Nygren P, Huffman LH, Nelson HD.. Complementary and alternative therapies for the management of menopause-related symptoms: a systematic evidence review. Arch Intern Med. 2006;166 (14): 1453-65.

16. Grochan E, Karakiewicz B, Karaliewicz T, Brodowski J.. Serum $\mathrm{Mg}$ and $\mathrm{Zn}$ levels in postmenopausal women. Magnes Res. 2011;24(4):209-14.

17. Naveenta G, Khushdeep S A . The Status of Trace Elements after Menopause: A Comparative Study. Journal of Clinical and Diagnostic Research, 2011;5 ( 4) : 795-97.

18. Ansar S, Alhefdhi T, Allem AM..Status of trace elements and antioxidants in premenopausal and post menopausal phase of life: A comparative Study. Int J Clin Exp Med. 2015; 8(10):19486-90. 